\title{
Risk-Adjusted Comparison of Blood Pressure and Low-Density Lipoprotein (LDL) Noncontrol in Primary Care Offices
}

\author{
Karl Hammermeister, MD, Michael Bronsert, PhD, William G. Henderson, PhD, MPH, \\ Letoynia Coombs, MS, EdD, Patrick Hosokawa, MS, Elias Brandt, BS, \\ Cathy Bryan, MHA, BSN, RN, Robert Valuck, PhD, RPh, David West, PhD, \\ Winston Liaw, MD, Michael Ho, MD, PhD, and Wilson Pace, MD
}

Objectives: Population-level control of modifiable cardiovascular disease (CVD) risk factors is suboptimal. The objectives of this study were (1) to demonstrate the use of electronically downloaded electronic health record (EHR) data to assess guideline concordance in a large cohort of primary care patients, (2) to provide a contemporary assessment of blood pressure (BP) and low-density lipoprotein (LDL) noncontrol in primary care, and (3) to demonstrate the effect of risk adjustment of rates of noncontrol of BP and LDL for differences in patient mix on these clinic-level performance measures.

Methods: This was an observational comparative effectiveness study that included 232,172 adult patients $\geq 18$ years old with $\geq 1$ visit within 2 years in 33 primary care clinics with EHRs. The main measures were rates of BP and LDL noncontrol based on current guidelines and were calculated from electronically downloaded EHR data. Rates of noncontrol were risk-adjusted using multivariable models of patient-level variables.

Results: Overall, $16.0 \%$ of the 227,122 patients with known BP and $14.9 \%$ of the 136,771 patients with known LDL were uncontrolled. Clinic-level, risk-adjusted BP noncontrol ranged from $7.7 \%$ to $26.5 \%$, whereas that for LDL ranged from $5.8 \%$ to $23.6 \%$. Rates of noncontrol exceeded an achievable benchmark for $85 \%$ $(n=28)$ and $79 \%(n=26)$ of the 33 clinics for BP and LDL, respectively. Risk adjustment significantly influences clinic rank order for rate of noncontrol.

Conclusions: We demonstrated that the use of electronic collection of data from a large cohort of patients from fee-for-service primary care clinics is feasible for the audit of and feedback on BP and LDL noncontrol. Rates of noncontrol for most clinics are substantially higher than those achievable. Risk adjustment of noncontrol rates results in a rank-order of clinics very different from that achieved with nonadjusted data. ( $\mathrm{J}$ Am Board Fam Med 2013;26:658-668.)

Keywords: Blood Pressure, Cholesterol, Clinical Practice Guideline, Electronic Health Records, Feedback, Health Information Management

More than one-third of American adults have one or more of the following cardiovascular diseases

This article was externally peer reviewed.

Submitted 11 January 2013; revised 16 May 2013; accepted 23 May 2013.

From the Colorado Health Outcomes Program (KH, MB, WGH, PH, DW, WP), the Division of Cardiology (KH, MH), and the Department of Family Medicine (LC, DW, WP), University of Colorado School of Medicine, Aurora; the Department of Biostatistics and Informatics, Colorado School of Public Health, Aurora (WGH); the National Research Network, American Academy of Family Physicians, Leawood, KS (EB, WP); DI Consulting, Dallas, TX (CB); the Department of Clinical Pharmacy, Skaggs School of Pharmacy and Pharmaceutical Sciences, University of Colorado, Aurora (RV); Fairfax Family Medicine
(CVDs): hypertension, coronary heart disease (CHD), stroke, or heart failure. In 2008 CVD was the primary cause of $32.8 \%$ of all US deaths. Similarly, CVD is the most common reason for hospi-

Residency Program, Virginia Commonwealth University, Fairfax (WL); and the Denver VA Medical Center, Denver, CO (MH).

Funding: This work was supported by The National Institutes of Health, National Heart, Lung, and Blood Institute Grant no. 1RC1HL101071-01.

Conflict of interest: none declared.

Corresponding author: Karl Hammermeister, MD, Colorado Health Outcomes Program, Mail Stop F443, UPI Building, 13199 East Montview Blvd., Suite 300, Room 334, Aurora, CO 80045 (E-mail: karl.hammermeister@ucdenver.edu). 
talization, accounting for $18 \%$ of the total of $34,369,000$ hospitalizations and one-fourth of the total cost of inpatient hospital care in the United States. ${ }^{1}$ Between 2010 and 2030, total direct medical costs of CVD (in real 2008 dollars) are projected to triple, from $\$ 273$ billion to $\$ 818$ billion. $^{2}$

Modifiable risk factors account for most CVD. The Atherosclerosis Risk in Communities Study followed 14,162 middle-aged adults who were free of recognized CVD at entry for a mean of 13.1 years. ${ }^{3}$ The vast majority ( $86.2 \%$ ) of the 1492 CVD events occurred in the $66.5 \%$ of the population with $\geq 1$ risk factor. The population-attributable fraction suggested that having at least 1 elevated risk factor accounted for $70.2 \%$ of CVD events.

Despite effective antihypertensive and antihyperlipidemic medications that have been shown to reduce major adverse cardiovascular events (MACEs) in large-scale, randomized trials, ${ }^{4,5}$ the control of blood pressure (BP) and cholesterol in the United States remains suboptimal. National Health and Nutrition Examination Survey (NHANES) data from 2005 to 2006 showed that $20.3 \%$ of US adults had uncontrolled BP (defined as $\geq 140 / 90 \mathrm{mmHg}$ ). ${ }^{6}$ For each $10-\mathrm{mmHg}$ decrease in systolic $\mathrm{BP}$, the average risk of heart disease and stroke mortality decreases by $30 \%$ and 40\%, respectively. ${ }^{7}$ An estimated 33,500,000 adults $\geq 20$ years old have total cholesterol levels $\geq 240 \mathrm{mg} / \mathrm{dL}$, a prevalence of $16.2 \% .{ }^{1,8}$ Cohort studies based on half a million men and 18,000 ischemic heart disease events estimate that a $10 \%$ long-term reduction in serum cholesterol would lower the risk of ischemic heart disease at age 40 by $50 \%$.?

The objectives of this article are to (1) demonstrate the use of electronically downloaded electronic health record (EHR) data to assess guideline concordance in a large cohort of primary care patients, (2) provide a contemporary assessment of noncontrol of BP and low-density lipoprotein (LDL) levels in primary care, and (3) demonstrate the effect of risk adjustment of rates of noncontrol of BP and LDL for differences in patient mix on these clinic-level performance measures.

\section{Methods}

\section{Study Design}

This is an observational study comparing evidencebased, risk-adjusted rates of noncontrol of $\mathrm{BP}$ and LDL across 33 clinics.

\section{Participants}

Table 1 shows the population characteristics. The mean (S.D.) age was 45.6 (15.7) years; body mass index (BMI) $27.7(6.2) \mathrm{kg} / \mathrm{M}^{2}$, and number of visits within two years 3.4 (5.0).

\section{Setting}

This study is being conducted in the Distributed Ambulatory Care Research in Therapeutics Network (DARTNet) Collaborative, a group of practice-based research networks that are working to build a national collection of EHR data. ${ }^{10-12}$ DARTNet, in collaboration with QED Clinical, Inc. (doing business as CINA; http://www.cina-us.com/), has developed data extraction, transformation, and loading (ETL) processes that allow aggregation of data from disparate EHRs into a harmonized database. The Cardiovascular Risk Reduction Learning Community (CRRLC) includes 33 primary care clinics from 10 private, fee-forservice health care delivery organizations participating in DARTNet. Two organizations were affiliated with a academic medical center, 1 provided sites for a community residency program affiliated with an academic medical center, and the remainder were not academically affiliated.

\section{Participants}

The study population consists of all $232,172 \mathrm{pa}-$ tients who met the overall criteria of age $\geq 18$ years and $\geq 1$ clinic appointment within the preceding 2 years.

\section{Guideline Translation to Calculate Rates of BP and LDL Noncontrol}

We relied extensively on the guidelines developed under of the auspices of the National Heart, Lung, and Blood Institute for control of BP (the Seventh Report of the Joint National Committee on Prevention, Detection, Evaluation, and Treatment of High Blood Pressure [JNC7] $)^{13}$ and LDL cholesterol (National Cholesterol Education Program [NCEP]). ${ }^{14}$ As have others, ${ }^{15}$ we found translating guidelines from their published, largely text format into algorithms suitable for electronic data analysis to be a challenging task requiring multiple revisions. Our CRRLC Steering Committee, comprising 4 primary care physicians recruited from participating clinics and 2 university-based subject matter experts, was central in resolving questions in this process. 
Figure 1. Flow diagram illustrating both criteria for blood pressure (BP) control from the Seventh Report of the Joint National Committee on Prevention, Detection, Evaluation, and Treatment of High Blood Pressure and the numbers (percentages) of patients at each step. CKD, chronic kidney disease.

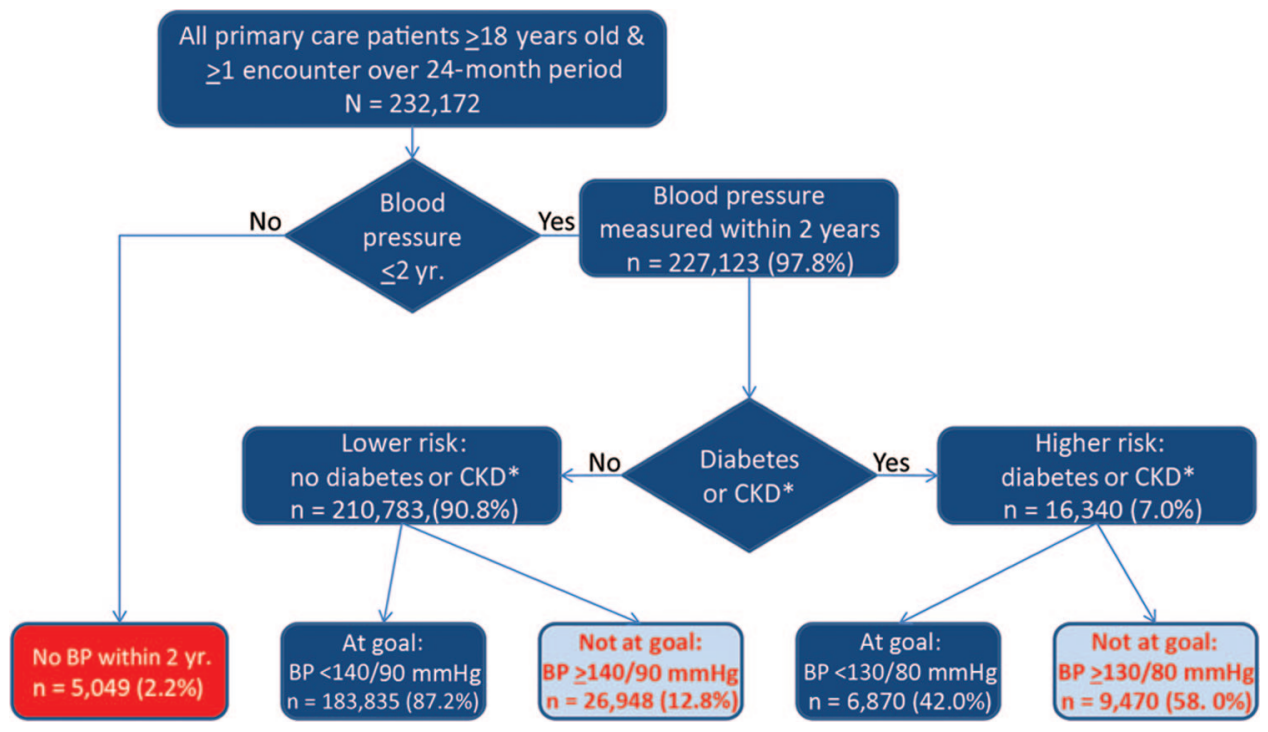

Calculation of noncontrol rates using both the JNC7 and NCEP guidelines required categorizing patients according to their risk for MACEs using CVD risk factors and presence or absence of CHD. The results of the translation of JNC7 and NCEP guidelines into hierarchical flow diagrams, on the basis of which electronic algorithms to calculate noncontrol rates were con-

Figure 2. Flow diagram illustrating National Cholesterol Education Program (NCEP) criteria for low-density lipoprotein (LDL) control and numbers (percentages) of patients at each step. *Coronary heard disease (CHD) equivalent includes diabetes, cerebral vascular disease, peripheral vascular disease, and abdominal aortic aneurysm. ${ }^{\dagger}$ NCEP nonlipid risk factors include age (male $>45$ years, female $>55$ years); family history of premature coronary artery disease; current cigarette smoking; hypertension (blood pressure $>140 / 90$ or taking antihypertensive medication); low high-density lipoprotein (HDL) $(>40 \mathrm{mg} / \mathrm{dL}$; if HDL $>60 \mathrm{mg} / \mathrm{dL}$, subtract one risk factor).

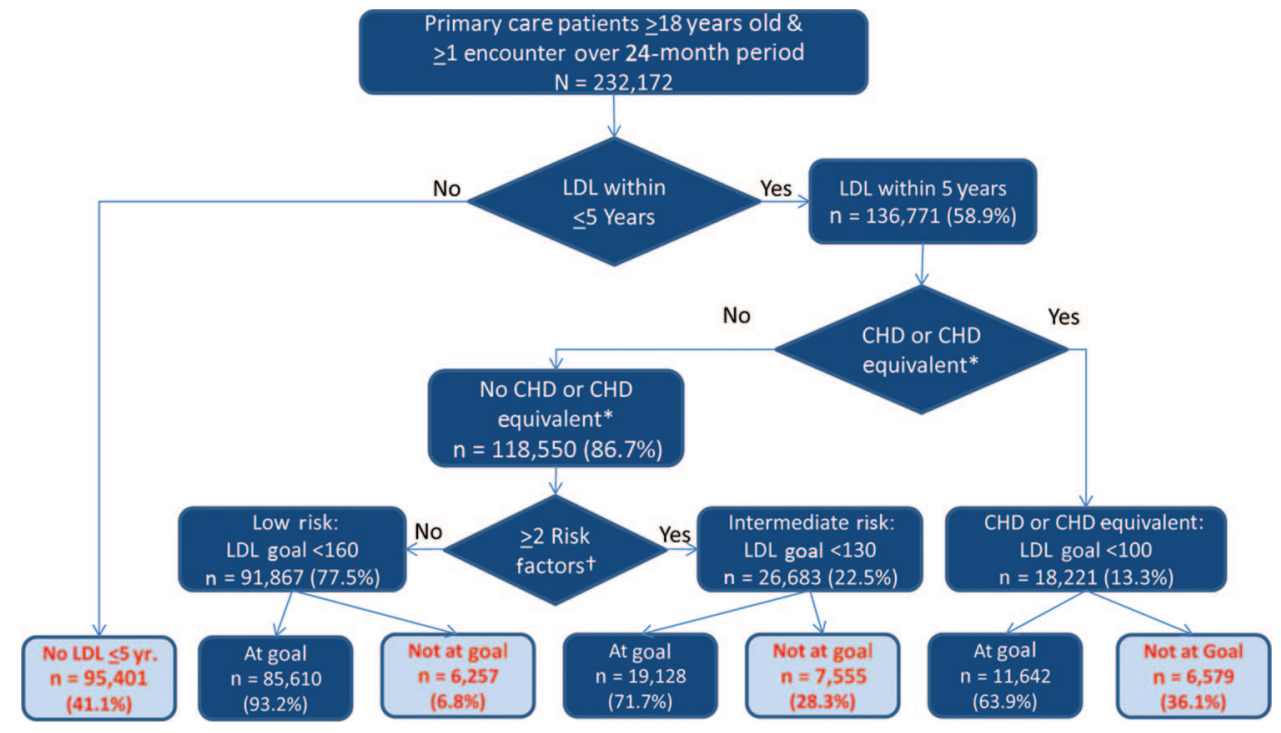


structed, are shown in Figures 1 and 2, respectively; additional details are provided in Appendix Tables 1 and 2, available online.

\section{Data Sources/Management}

The data reported here are drawn from EHR data about clinic visits, including problem lists, patient demographics, BP measurements, and laboratory data between January 1, 2006, and December 31, 2010. For both the JNC7 and NCEP guidelines, the data required to assess and adjust for risk the guideline noncontrol rates include $\mathrm{BP}$ and LDL measurements, concomitant comorbidity, and other risk factors for MACE (eg, age, cigarette smoking, and HDL-cholesterol). In addition, we collected data on clinic appointments and encounters, antihypertensive and antihyperlipidemic medications prescribed, height, weight, year of birth, and tobacco use/abuse. When $\geq 2$ BP measurements were available, we used the average of the 2 most recent values. Age, BP, LDL levels, and HDL levels are relatively easy to retrieve from the EHRs of CRRLC organizations, but the definition of comorbidities using International Classification of Diseases, Ninth Revision (ICD-9), codes requires grouping into clusters, which are not provided in either the complete $\mathrm{JNC}^{13}$ or $\mathrm{NCEP}^{14}$ documents. We used the clustering of ICD-9 codes into comorbidities developed for ambulatory care by Schneeweiss et $\mathrm{al}^{16}$ and subsequently modified by Pace et al. ${ }^{17}$ This grouping did not contain ICD-9 code clusters for chronic kidney disease and abdominal aortic aneurysm, which we created using our clinical judgment (Appendix Table 3, available online).

All data were imported nightly from the practice EHRs to a relational clinical data repository (CDR) located behind the firewall of each organization using proprietary software mapping tools developed by CINA. The CINA software used for ETL were tools that were already in place and being used by each organization to produce point-of-care clinical decision support reports and population management reports. The CDR provided a near realtime source of standardized and codified data used in point-of-care clinical decision making and the audit and feedback reports, as well as the periodic data extractions used for this article. CINA, which had a Business Associate Agreement already in place with each organization, served as our data transfer agent, providing us with the limited data sets required for the analyses reported here.

\section{Data Validation by CINA}

Because this research was conducted using data extracted and translated from the EHRs to a secondary CDR by our data transfer agent, CINA, it was imperative to understand and validate the data received through a multistep process. Data validation was largely the responsibility of CINA as the ETL vendor in place at each organization before the initiation of this project. Because CINA provides software tools that use data from the CDR in the course of clinical care and decision making, CINA has several processes in place to ensure the reliability and validity of the data that is contained within the CDR. Data reliability testing by CINA includes the following: (1) patient-level sampling comparing the data imported into the CDR with the source data as it is represented in the EHR; (2) daily use in clinical practice of the data in the CDR through the point-of-care clinical decision support tool and population management tools provided by CINA; and (3) data reliability testing with each data extraction for research analysis.

\section{Data Validation Exercises by the Investigators}

Data validation studies performed by the investigators included (1) an assessment of data distribution for continuous variables to identify implausible or nonphysiologic values; (2) comparisons of distributions of continuous variables by organization to look for problems with units (ie, English/metric), differing analytic methods, and mapping anomalies; and (3) an examination of the distribution of categorical responses to look for clinically conflicting findings. These data validation studies were done independent of CINA, but the results were shared with CINA for wider improvement in data quality.

We constructed tables of the distributions of each continuous variable that included the value, number, and percentage of each observation and cumulative percentage of all observations. In addition, we found that viewing graphs of these distributions as a group was useful. Using our clinical judgment and the proportions of values in the tails of the distributions, we excluded the following values from further analysis: systolic BP $>260$ or $<50$ $\mathrm{mmHg}$, diastolic $\mathrm{BP}>200$ or $<0 \mathrm{mmHg}$, height $>90^{\prime \prime}$ or $<45^{\prime \prime}$, weight $>500$ or $<50 \mathrm{lb}$, creatinine $>20$ or $<0.2 \mathrm{mg} / \mathrm{dL}$, total cholesterol $>450$ or $<50 \mathrm{mg} / \mathrm{dL}, \mathrm{LDL}>300$ or $<10 \mathrm{mg} / \mathrm{dL}$, and HDL-cholesterol $>150$ or $<5 \mathrm{mg} / \mathrm{dL}$. The pro- 
portion of values deleted varied from $0.005 \%$ for systolic BP to $0.5 \%$ for creatinine.

When comparing distributions of data by clinic, we discovered a few anomalies, one of which was due to one organization using a different cholesterol fractionation technique; others probably were due to mapping variances. These anomalies were corrected in most cases by examining the organization-specific field names. Short of manual chart review—a nearly impossible task for 232,172 patients-there is no way to check the accuracy of ICD-9 coding of comorbidities in the EHR, which enter into the calculation of guideline concordance and its risk adjustment; therefore we accepted the ICD-9 coding without editing or verification.

A value for $\mathrm{BP}$ in the preceding 2 years was missing in only $2.2 \%$ (5,049 of 232,272 patients) of patients; a value for LDL in the preceding 5 years was missing for in $41.1 \%$ (95,401 of $232,172 \mathrm{pa}-$ tients); and height and weight were missing in $9.0 \%$ and $2.7 \%$, respectively. These missing values were not imputed, meaning that the sample sizes in the multivariable models were reduced (Appendix Tables 4 and 5, available online).

\section{Data Security and Privacy Protection}

Each of the 10 participating organizations signed a data use agreement allowing the use of their data; this agreement specifies the data elements used and that Health Insurance Portability and Accountability Act identifiers, with the exception of dates of service, were deleted before transfer to a secure server within the Department of Family Medicine at the University of Colorado School of Medicine.

\section{Institutional Review Board}

The protocol for the CRRLC, a waiver of informed consent, and a waiver of Health Insurance Portability and Accountability Act authorization have been approved by the Colorado Multiple Institutional Review Board and an institutional review board sponsored by the American Academy of Family Physicians that represents all participating clinics.

\section{Statistical Analyses}

We used previous research and our clinical judgment to select the 31 variables (listed in Table 1) to describe the cohort and to develop risk-adjustment models using stepwise logistic regression with BP or LDL noncontrol as the dependent variables.
Table 1. Population Characteristics $(n=232,172)$

\begin{tabular}{|c|c|}
\hline $\begin{array}{l}\text { Selected Patient Characteristics and } \\
\text { Risk-Adjustment Variables }\end{array}$ & Prevalence \\
\hline Adverse drug effects & $1,134(0.49)$ \\
\hline \multicolumn{2}{|l|}{ Age (years) } \\
\hline $18-40$ & $95,639(41.2)$ \\
\hline $41-60$ & $94,978(40.9)$ \\
\hline $61-80$ & $35,971(15.5)$ \\
\hline$>80$ & $5,584(2.4)$ \\
\hline Alcohol or drug abuse & $11,326(4.9)$ \\
\hline Anemia & $10,442(4.5)$ \\
\hline \multicolumn{2}{|l|}{ Body mass index $\left(\mathrm{kg} / \mathrm{m}^{2}\right)$} \\
\hline$<18.5$ (underweight) & $3,557(1.5)$ \\
\hline $18.5-24.9$ (normal) & $67,834(29.2)$ \\
\hline 25.0-29.9 (overweight) & $73,852(31.8)$ \\
\hline 30.0-34.9 (class I obese) & $39,744(17.1)$ \\
\hline 35.0-39.9 (class II obese) & $16,041(6.9)$ \\
\hline$\geq 40.0$ (class III obese) & $9,967(4.3)$ \\
\hline Missing & $21,177(9.1)$ \\
\hline Cataract/aphakia & $4,081(1.8)$ \\
\hline Cerebral vascular disease or CVA & $3,612(1.6)$ \\
\hline Congestive heart failure & $1,518(0.7)$ \\
\hline Depression or anxiety & $50,822(21.9)$ \\
\hline Diabetes mellitus & $14,804(6.4)$ \\
\hline Ischemic heart disease & $6,007(2.6)$ \\
\hline Hepatitis or mononucleosis & $2,356(1.0)$ \\
\hline Hyperlipidemia & $65,343(28.1)$ \\
\hline Hypertension & $58,849(25.3)$ \\
\hline Chronic kidney disease & 2,667 (1.1) \\
\hline Male sex & $101,184(43.6)$ \\
\hline Medical or surgical aftercare & $12,871(5.5)$ \\
\hline Neoplasm, benign & $26,926(11.6)$ \\
\hline Neoplasm, malignant & 3,308 (1.4) \\
\hline Obesity & $16,089(6.9)$ \\
\hline Peripheral vascular disease & $1,835(0.8)$ \\
\hline Personality disorders & $192(0.1)$ \\
\hline Pulmonary disease, chronic obstructive & $3,709(1.6)$ \\
\hline Prostatitis/BPH & $7,821(3.4)$ \\
\hline Psychosocial problem & $1,463(0.6)$ \\
\hline Respiratory tract infection, acute lower & $22,820(9.8)$ \\
\hline Respiratory tract infection, acute upper & $47,984(20.7)$ \\
\hline Rhinitis, chronic & $49,977(21.5)$ \\
\hline Routine health maintenance & $126,419(54.5)$ \\
\hline Schizophrenia or affective psychosis & $5,660(2.4)$ \\
\hline \multicolumn{2}{|l|}{ Visits per year (n) } \\
\hline 1 or 2 & $141,393(60.9)$ \\
\hline 3 or 4 & $47,948(20.7)$ \\
\hline 5 or 6 & $17,764(7.7)$ \\
\hline$>6$ & $25,067(10.8)$ \\
\hline
\end{tabular}

Data are $\mathrm{n}(\%)$.

$\mathrm{BPH}$, benign prostatic hyperplasia; CVA, cerebrovascular accident. 
The cumulative c-index was computed after each step.

We calculated the risk of each patient having BP or LDL noncontrol using the parameter estimates from each model and summed this expected risk by clinic (E), which was compared with the observed number of patients with noncontrol $(\mathrm{O})$ in each clinic as the O-to-E ratio. For ease of clinical interpretation we converted the $\mathrm{O}$-to-E ratio into a risk-adjusted percentage of noncontrol by multiplying each clinic's O-to-E ratio by the observed mean rate of noncontrol for all patients across all clinics. We calculated an achievable benchmark of care patterned after the work of Kiefe and colleagues, ${ }^{18-21}$ except clinics were rank-ordered by their risk-adjusted rates of noncontrol. Our achievable benchmark is the weighted average noncontrol rate for the top-ranked clinics, providing care for approximately $10 \%$ of all patients.

\section{Results}

\section{Unadjusted BP Noncontrol}

There was no BP measurement within the preceding 2 years for $2.2 \%$ of patients $(5,049$ of 232,172$)$. Overall, $16.0 \%$ of patients $(36,418$ of 227,123$)$ with measured BPs had uncontrolled BP (Figure 1). For patients without diabetes or CKD, 12.8\% (26,948 of $210,783)$ had uncontrolled BP $(\geq 140 / 90 \mathrm{mmHg}$ ). For patients with diabetes or CKD, 58.0\% (9,470 of 16,340) had uncontrolled BP ( $\geq 130 / 80 \mathrm{mmHg})$.

\section{Risk-Adjusted BP Noncontrol}

The multivariable model of patient-level variables associated with BP noncontrol is shown in Appen-

Figure 3. Comparison of rank-order of clinics by unadjusted and risk-adjusted blood pressure (BP) control.

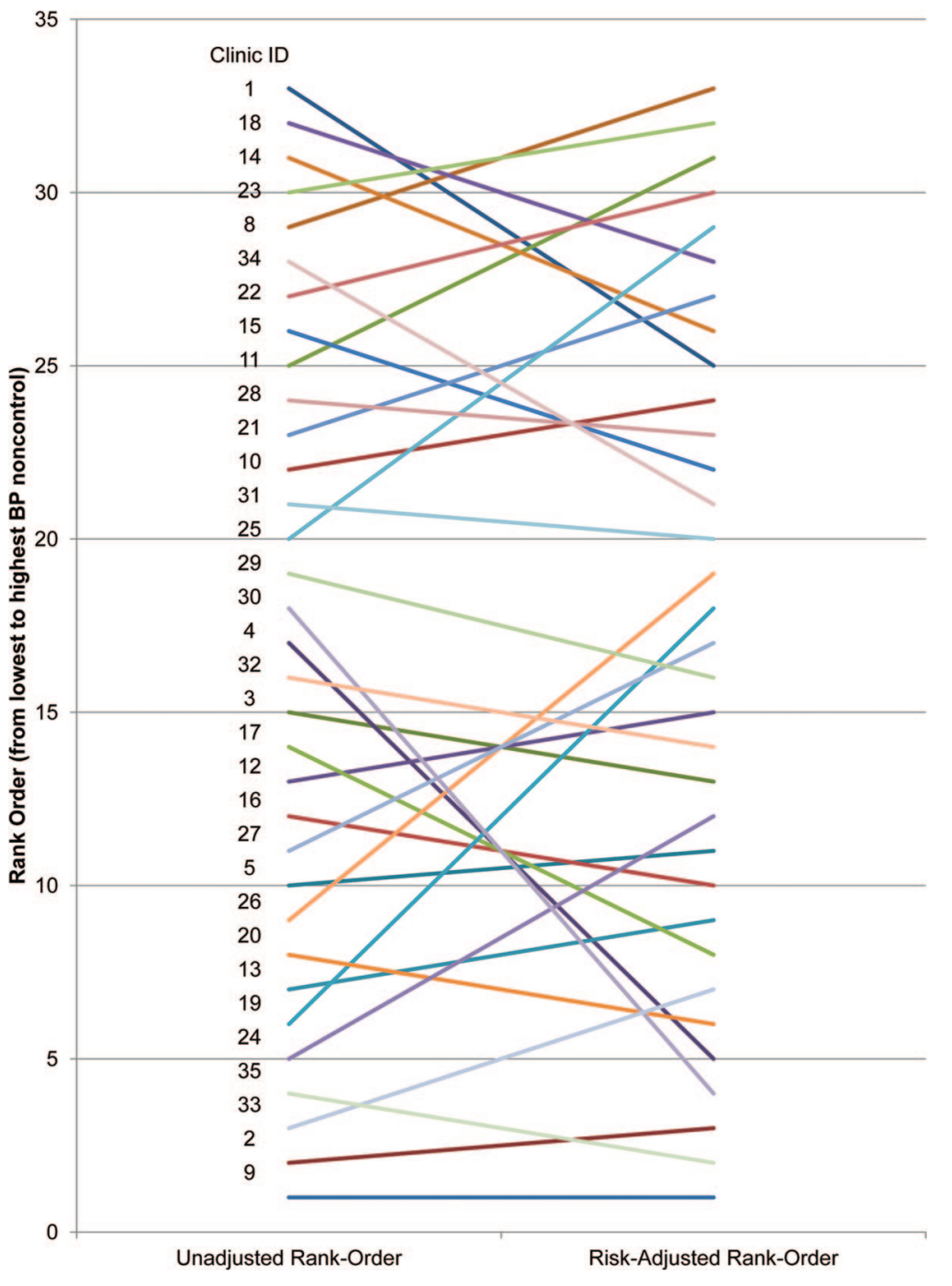


dix Table 4, available online. The c-index for the full model was 0.822 , whereas the c-index for the first 10 variables entering the model, which were used in the risk adjustment of BP noncontrol, was 0.821. Online Appendix Figure 1 shows the riskadjusted percentage of noncontrol by clinic, which varied from a high of $26.5 \%$ to a low of $7.7 \%$, with a weighted average across all clinics of $15.9 \%$. The achievable benchmark was $10.7 \%$ noncontrol. Of the 33 clinics, 28 (85\%) had noncontrol rates with 95\% confidence intervals higher than this benchmark.

Figure 3 shows the considerable differences the rank-order of clinics by the unadjusted rate of BP noncontrol versus the rank-order of the risk-adjusted noncontrol rate, with 4 clinics changing rank-order by $\geq 10$ places, 8 clinics changing rankorder between 5 and 9 places, and 21 clinics changing rank-order $\leq 4$ places.

\section{Unadjusted LDL Noncontrol}

LDL measurements within the preceding 5 years, the maximum interval between measurements recommended by the NCEP ${ }^{14}$ were not retrievable electronically from the EHR for $41.1 \%$ of patients. Overall, $14.9 \%$ of patients $(20,391$ of 136,771$)$ with measurements had uncontrolled LDL (Figure 2). The degree of LDL noncontrol varied markedly with patient risk, from $36.1 \%$ for patients with $\mathrm{CHD}$ or CHD equivalent (highest risk) to $28.3 \%$ for patients with no CHD or CHD equivalent but with $\geq 2$ risk factors (intermediate risk), to $6.8 \%$ for low-risk patients.

\section{Risk-Adjusted LDL Noncontrol}

Variables predictive of LDL noncontrol from a logistic regression model are shown in Appendix Table 5, available online. The c-index for the full model was 0.737 ; the cumulative c-index for the first 10 variables used for risk-adjustment is 0.734 . Online Appendix Figure 2 shows the risk-adjusted percentage of LDL noncontrol by clinic, which varied from $5.8 \%$ to $23.6 \%$. The mean noncontrol for all clinics was $13.4 \%$, while the 3 best-performing clinics set the benchmark at $11.2 \%$; 26 of the 33 clinics $(79 \%)$ had noncontrol rates with $95 \%$ confidence intervals higher than this benchmark.

Again, there were marked differences in clinic rank-order based on the nonadjusted rates of noncontrol from that based on the risk-adjusted rate of noncontrol (Figure 4). Six clinics experienced a change in rank order of $\geq 10$ places, whereas 8 clinics changed rank-order between 5 and 10 places and 19 changed rank order $\leq 4$ places. This is due to differences in the distribution of variables predictive of BP and LDL control by clinic (Appendix Tables 4 and 5, available online). Failure to adjust for risk could lead clinics to attribute high rates of noncontrol to the often nonmutable characteristics of their patients (eg, age, sex, and a diagnosis of diabetes) and preclude making changes in processes or structures of care.

\section{Discussion}

\section{Key Results}

While the EHRs of only $2.2 \%$ of patients were missing all $\mathrm{BP}$ values within the 2 previous years, $41.1 \%$ were missing LDL values within the previous 5 years. Of patients with known values, $16.0 \%$ and $14.9 \%$ failed to meet guideline recommendations for BP control and LDL control, respectively; however, a large majority of clinics had noncontrol rates in excess of those achieved by the best-performing clinics, indicating substantial room for improvement. Ranking of clinics by risk-adjusted rates of noncontrol was markedly different from ranking by unadjusted rates of noncontrol, indicating the importance of risk adjustment.

\section{Strengths and Limitations}

The strengths of this study include the large primary care patient population, the inclusion of all patients within a clinic $\geq 18$ years of age and with $\geq 1$ clinic visit within the preceding 2 years, inexpensive electronic data collection, risk adjustment of the clinic-level outcomes of BP and LDL noncontrol, and the electronic assessment of patientlevel noncontrol per JNC7 and NCEP.

Limitations include (1) limited clinic-level data, precluding comparison of characteristics of high and low outlier clinics; 2) incomplete data on race/ ethnicity; (3) a large proportion of patients (41.1\%) had no LDL measurement within the preceding 5 years retrievable as a discrete data field from the EHR; (4) the participating clinics are not representative of the full range of US ambulatory care; (5) some providers question the validity of EHR data; and (6) the absence of data on MACEs.

\section{Missing LDL Data}

The reliability of our assessment of LDL control must be interpreted in light of the fact that $41.1 \%$ 
Figure 4. Comparison of rank-order of clinics by unadjusted and risk-adjusted low-density lipoprotein (LDL) cholesterol control.

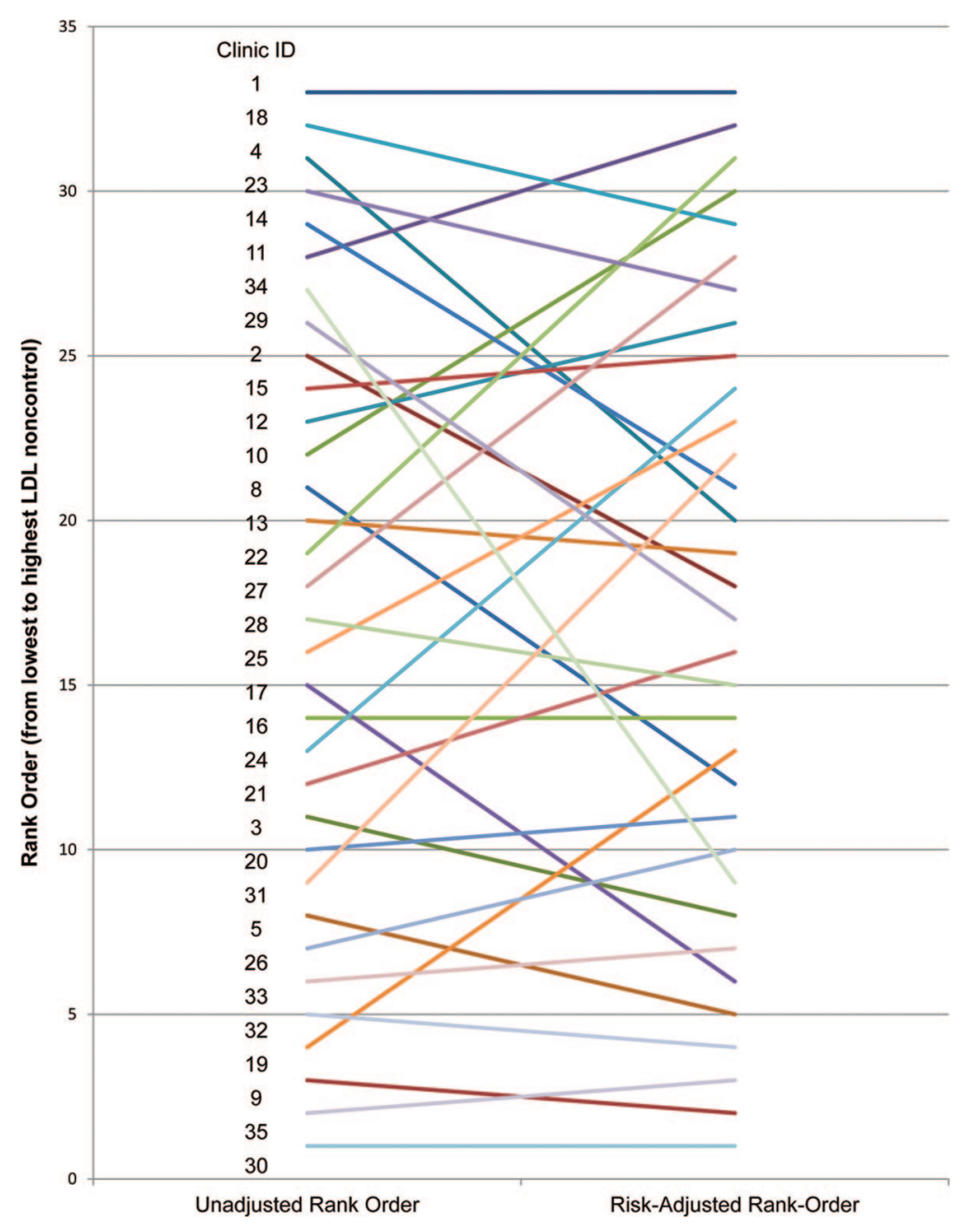

of patients had no LDL value available in a discrete EHR field for the preceding 5 years. We recognize that an LDL value measured at another health care organization may have been recorded as a text note, but we made no attempt to retrieve data from text notes. More important, numeric data buried in a text note is difficult for the care provider or organization to retrieve. A companion article currently under review for publication will report the timeliness of BP and LDL measurements.

\section{Representativeness of the Patient Population}

The health care organizations included in this study are not a representative sample of US ambulatory care in the sense that there is no representation of other major models of ambulatory care delivery, such as private integrated systems like Kaiser, government-integrated systems like the
Veterans Affairs, and community health centers providing care for the large underserved segment of our population. Although we do not have the data, we believe that DARTNet clinics are at least somewhat representative of private, nonintegrated, fee-for-services clinics. The 33 clinics in this study include urban, academic-affiliated clinics as well as suburban and rural clinics, and they vary in size from a single physician supported by 1 or 2 paraprofessionals to group practices of $\geq 30$ primary care physicians in multiple suburban locations.

\section{Doubts about the Validity of EHR Data}

It is our view that the EHR will play an increasingly critical role in both the delivery of health care and the assessment of that delivery. EHRs have an enormous advantage over paper records in costeffectively aggregating data from large groups of 
patients. In a recent supplement of Medical Care about electronic data methods, Randhawa and Slutsky, ${ }^{22}$ from the Center for Outcomes and Evidence, Agency for Health Care Research and Quality, expressed this view more cogently: "The challenge of addressing complex questions, such as what affects patient outcomes in a real-world clinical setting, demands a scalable electronic infrastructure that can provide high-quality, clinically rich, prospective, multi-site data for generating internally valid and generalizable conclusions in a timely and efficient manner." The current article comes from the DARTNet, which was initially funded by the Agency for Health Care Research and Quality to respond to the challenge posed by Randhawa and Slutsky.

We delivered electronically to the point of care patient-specific clinical decision support, which consisted of graphic displays of BP, LDL, and all antihypertensive and antihyperlipidemic prescriptions over time. In addition, audit and feedback of aggregate clinical data similar to that shown in Figures 1 and 2 and online Appendix Figures 1 and 2 were provided to all care providers on 2 occasions. While our care provider surveys showed that only a minority regularly use these reports, we received virtually no expressions of concern regarding the validity of these data. Before instituting the clinical decision support, these reports were reviewed and approved by our Steering Committee. Our time series assessment of guideline concordance unfortunately showed little change, which we now attribute to our failure to adequately engage the care providers. We are planning to report those data in a separate article.

\section{Data Quality}

It is common practice to perform extensive validation of data manually abstracted from paper medical records for clinical research. Validation methods include (1) cross-checking important concepts against several sources of data; (2) checking for illogical data combinations (eg, pregnancy in a male); (3) assessing the accuracy of diagnostic coding by comparing the narrative record against standardized definitions; (4) conducting inter- and intraobserver variability assessments; and (5) excluding unreasonable values in distributions of continuous data. We did only the latter because numbers 1 through 4 above are not routinely performed when working with EHR data since the data as it exists in the EHR is the same data that is being used for clinical decision making; therefore, the practice and provider have a medical/legal obligation for accuracy. Also, laborious and expensive data validation negates an important advantage of EHR data: the ability to inexpensively and quickly collect and analyze data from large numbers of patients. In the context of this study, the ultimate data validation should come in the form of credibility of the results to care providers and improvement of patient outcomes. Finally, in a literature search we were unable to find publications of validation of ambulatory care EHR data against source data.

\section{Use of Electronic Data Collection to Assess Guideline Concordance}

We have demonstrated the ability to assess guideline concordance using electronic data collection for 232,172 patients in 33 clinics comprising 10 private, fee-for-service health care organizations with disparate EHRs. Despite daily feedback of patient-specific clinical decision support and 2 cycles of audit and feedback, no credibility issues have been raised by participants in this study.

The costs of data collection and management per patient over 2 years of $\$ 2.98$ and $\$ 4.31$, respectively, based on the grant's direct and combined direct and indirect costs, are not intended as a formal cost analysis but as an estimate only. The ultimate value of electronically supported interventions to reduce MACEs must compare the costs of delivery of the intervention to the cost savings from reduced MACEs.

\section{Rates of BP and LDL Noncontrol}

The rates of BP and LDL noncontrol in this study are better than those previously reported. The Centers for Disease Control and Prevention, ${ }^{6}$ reporting NHANES data from 10,037 adults aged $\geq 18$ years from 2005 to 2008 , found that $20.3 \%$ $(2,108$ of 10,037$)$ had uncontrolled hypertension defined as $\mathrm{BP} \geq 140 / 90 \mathrm{mmHg}$. We found $16.0 \%$ to have uncontrolled BP using the JNC7 definition $(<130 / 80 \mathrm{mmHg}$ for patients with diabetes or chronic kidney disease, $<140 / 90 \mathrm{mmHg}$ otherwise); if we applied the NHANES definition, the noncontrol rate was $13.5 \%$. There are several possible explanations for the lower rates of noncontrol in our study: (1) CRRLC patients are being seen in fee-for-service clinics, meaning that they have a primary care provider and are likely of higher socioeco- 
nomic status in contrast to the NHANES sample, which was specifically designed to be representative of the US population. (2) Similarly, the racial/ethnic distribution in our population may be different in a direction favoring better $\mathrm{BP}$ control than that of NHANES. (3) BP control may have improved from the time of NHANES data collection (2005-2008) to that of this report (2009-2010).

Reporting NHANES data from 2005 to 2008 and using the same NCEP criteria as we used, the Centers for Disease Control and Prevention ${ }^{23}$ also found that $21.2 \%$ had uncontrolled LDL, compared with the $14.9 \%$ we found. In addition to the caveats for hypertension listed above, $41.1 \%$ of our overall population did not have a LDL measurement within 5 years, as recommended by NCEP, and were excluded; this could lead to a large bias in our results.

Risk adjustment of adverse postoperative outcomes in surgery as a quality measure has become common since its introduction more than 2 decades ago. ${ }^{24-29}$ Risk-adjusted outcomes as a measure of quality in surgery have been validated against data from site visits ${ }^{29,30}$ and are now widely accepted in surgical care. Processes of care (eg, prescribing a statin for patients with CHD), surrogate outcomes (eg, BP and LDL measures), and true outcomes (eg, mortality) are being used increasingly to assess the quality of nonsurgical care. While mortality is often adjusted for patient risk, we have been unable to find published reports in which comparisons of guideline concordance between providers have been adjusted for patient factors associated with concordance. Our multivariable models show that comorbidity has important effects on both BP and LDL control. Clinics with a disproportionate number of these patients may be unfairly ranked higher by unadjusted rates of noncontrol because these risk factors are relatively immutable.

\section{Generalizability}

This study should be generalizable to other fee-forservice primary care clinics using EHRs. Care should be taken when applying these results to primary care in other settings, such as integrated health care systems or federally qualified health clinics providing care to the underserved.

\section{Clinical and Research Implications}

Although the rates of $\mathrm{BP}$ and LDL noncontrol in this study seem to be better than those in reports based on the most recent NHANES data, ${ }^{6,23}$ this is not a reason for complacency. The $16.0 \%$ of pri- mary care patients with uncontrolled BP and $14.9 \%$ with uncontrolled LDL represent substantial opportunities to reduce the morbidity, mortality, and the costs of care due to MACEs. This reduction in mortality, morbidity, and cost of care needs to be demonstrated in a large-scale randomized trial; achieving the large sample size needed ( $\sim 600,000$ patients) will require electronically facilitated data collection and interventions, as we have demonstrated here.

The authors thank the CRRLC Steering Committee: Edward Bujold, MD, Family Medical Center, Granite Falls, NC; Cynthia Croy, MD, Family Health Center of Joplin, Joplin, MO; Michael Ho, MD, PhD, Denver VA Medical Center and University of Colorado School of Medicine, Denver, CO; Winston Liaw, MD, Fairfax Family Practice, Fairfax, VA; Jamie Reedy, MD, Westfield Family Practice at Summit Medical Group, Westfield, NJ; and Stephen Ross, MD, University of Colorado School of Medicine, Aurora, CO.

\section{References}

1. Roger VL, Go AS, Lloyd-Jones DM, et al. Heart disease and stroke statistics-2012 update: a report from the American Heart Association. Circulation 2012;125:e2-220.

2. Heidenreich PA, Trogdon JG, Khavjou OA, et al. Forecasting the future of cardiovascular disease in the United States: a policy statement from the American Heart Association. Circulation 2011;123: 933-44.

3. Hozawa A, Folsom AR, Sharrett AR, Chambless LE. Absolute and attributable risks of cardiovascular disease incidence in relation to optimal and borderline risk factors: comparison of African American with white subjects--Atherosclerosis Risk in Communities Study. Arch Intern Med 2007;167:573-9.

4. Law MR, Morris JK, Wald NJ. Use of blood pressure lowering drugs in the prevention of cardiovascular disease: meta-analysis of 147 randomised trials in the context of expectations from prospective epidemiological studies. BMJ 2009;338:b1665.

5. Baigent C, Keech A, Kearney PM, et al. Efficacy and safety of cholesterol-lowering treatment: prospective meta-analysis of data from 90,056 participants in 14 randomised trials of statins. Lancet 2005;366: $1267-78$.

6. Centers for Disease Control and Prevention (CDC). Vital signs: prevalence, treatment, and control of hypertension-United States, 1999-2002 and 20052008. MMWR Morb Mortal Wkly Rep 2011;60: $103-8$.

7. Lewington S, Clarke R, Qizilbash N, Peto R, Collins R. Age-specific relevance of usual blood pressure to vascular mortality: a meta-analysis of individual data for one million adults in 61 prospective studies. Lancet 2002;360:1903-13. 
8. Fryar CD, Hirsch R, Eberhardt MS, Yoon SS, Wright JD. Hypertension, high serum total cholesterol, and diabetes: racial and ethnic prevalence differences in U.S. adults, 1999-2006. NCHS Data Brief 2010;1-8.

9. Law MR, Wald NJ, Thompson SG. By how much and how quickly does reduction in serum cholesterol concentration lower risk of ischaemic heart disease? BMJ 1994;308:367-72.

10. Libby AM, Pace W, Bryan C, et al. Comparative effectiveness research in DARTNet primary care practices: point of care data collection on hypoglycemia and over-the-counter and herbal use among patients diagnosed with diabetes. Med Care 2010; 48(6 Suppl):S39-44.

11. Pace WD, Cifuentes M, Valuck RJ, Staton EW, Brandt EC, West DR. An electronic practice-based network for observational comparative effectiveness research. Ann Intern Med 2009;151:338-40.

12. Pace WD, West DR, Valuck RJ, Cifuentes M, Staton EW. Distributed Ambulatory Research in Therapeutics Network (DARTNet): summary report. Effective health care research reports, no. 14. Rockville, MD: Agency for Healthcare Research and Quality; 2009. Available from: http://effectivehealthcare.ahrq.gov/ehc/products/53/ 151/2009_0728DEcIDE_DARTNet.pdf. Accessed September 19, 2013.

13. Chobanian AV. The Seventh Report of the Joint National Committee on Prevention, Detection, Evaluation, and Treatment of High Blood Pressure: complete report. National Institutes of Heath publication no. 04-5230. Bethesda, MD: National Heart, Lung, and Blood Institute; 2004. Available from: http://www.nhlbi.nih.gov/guidelines/hypertension/ jnc7full.htm. Accessed September 19, 2013.

14. National Cholesterol Education Program (NCEP) Expert Panel on Detection, Evaluation, and Treatment of High Blood Cholesterol in Adults (Adult Treatment Panel III). Third Report of the National Cholesterol Education Program (NCEP) Expert Panel on Detection, Evaluation, and Treatment of High Blood Cholesterol in Adults (Adult Treatment Panel III) final report. Circulation 2002;106:3143-421.

15. Tierney WM, Overhage JM, Takesue BY, et al. Computerizing guidelines to improve care and patient outcomes: the example of heart failure. J Am Med Inform Assoc 1995;2:316-22.

16. Schneeweiss R, Rosenblatt RA, Cherkin DC, Kirkwood CR, Hart G. Diagnosis clusters: a new tool for analyzing the content of ambulatory medical care. Med Care 1983;21:105-22.

17. Pace WD, Dickinson LM, Staton EW. Seasonal variation in diagnoses and visits to family physicians. Ann Fam Med 2004;2:411-7.
18. Kiefe C, Woolley TW, Allison JJ, Box JB, Craig AS. Determining benchmarks: a data-driven search for the best achievable performance. Clin Perfor Qual Health Care 1994;2:190-4.

19. Kiefe CI, Weissman NW, Allison JJ, Farmer R, Weaver M, Williams OD. Identifying achievable benchmarks of care: concepts and methodology. Int J Qual Health Care 1998;10:443-7.

20. Kiefe CI, Allison JJ, Williams OD, Person SD, Weaver MT, Weissman NW. Improving quality improvement using achievable benchmarks for physician feedback: a randomized controlled trial. JAMA 2001;285:2871-9.

21. Weissman NW, Allison JJ, Kiefe CI, et al. Achievable benchmarks of care: the ABCs of benchmarking. J Eval Clin Pract 1999;5:269-81.

22. Randhawa GS, Slutsky JR. Building sustainable multi-functional prospective electronic clinical data systems. Med Care 2012;50(Suppl):S3-6.

23. Centers for Disease Control and Prevention (CDC). Vital signs: prevalence, treatment, and control of high levels of low-density lipoprotein cholesterolUnited States, 1999-2002 and 2005-2008. MMWR Morb Mortal Wkly Rep 2011;60:109-14.

24. Grover FL, Hammermeister KE, Burchfiel C. Initial report of the Veterans Administration Preoperative Risk Assessment Study for Cardiac Surgery. Ann Thorac Surg 1990;50:12-26.

25. Marshall G, Grover FL, Henderson WG, Hammermeister KE. Assessment of predictive models for binary outcomes: an empirical approach using operative death from cardiac surgery. Stat Med 1994;13:1501-11.

26. Grover FL, Johnson RR, Shroyer AL, Marshall G, Hammermeister KE. The Veterans Affairs Continuous Improvement in Cardiac Surgery Study. Ann Thorac Surg 1994;58:1845-51.

27. Hammermeister KE, Johnson R, Marshall G, Grover FL. Continuous assessment and improvement in quality of care. A model from the Department of Veterans Affairs Cardiac Surgery. Ann Surg 1994; 219:281-90.

28. Daley J, Khuri SF, Henderson W, et al. Risk adjustment of the postoperative morbidity rate for the comparative assessment of the quality of surgical care: results of the National Veterans Affairs Surgical Risk Study. J Am Coll Surg 1997;185:328-40.

29. Khuri SF, Daley J, Henderson W, et al. Risk adjustment of the postoperative mortality rate for the comparative assessment of the quality of surgical care: results of the National Veterans Affairs Surgical Risk Study. J Am Coll Surg 1997;185:315-27.

30. Daley J, Forbes MG, Young GJ, et al. Validating risk-adjusted surgical outcomes: site visit assessment of process and structure. National VA Surgical Risk Study. J Am Coll Surg 1997;185:341-51. 
Appendix Table 1. International Classification of Diseases, Ninth Revision (ICD-9), Code Criteria for Comorbidity and Coronary Heart Disease Risk Factors Used to Construct a Seventh Report of the Joint National Committee on Prevention, Detection, Evaluation, and Treatment of High Blood Pressure (BP) Guideline Concordance Algorithm*

\begin{tabular}{|c|c|c|}
\hline Classification & Disease & ICD-9 Code \\
\hline \multirow[t]{9}{*}{$\begin{array}{l}\text { I. Higher risk (BP goal }<130 / 80 \\
\text { mmHg) }\end{array}$} & Diabetes & $\begin{array}{l}\text { 249.xx, Secondary diabetes mellitus } \\
\text { 250.xx, Diabetes mellitus }\end{array}$ \\
\hline & Chronic kidney disease & 403.xx, Hypertensive chronic kidney disease \\
\hline & & 404.xx, Hypertensive heart and chronic kidney disease \\
\hline & & $\begin{array}{l}\text { 581, Nephrotic syndrome } \\
\text { 582, Chronic glomerulonephritis }\end{array}$ \\
\hline & & $\begin{array}{l}\text { 585.x, Chronic kidney disease } \\
\text { 585, Renal failure, unspecified }\end{array}$ \\
\hline & & $\begin{array}{l}\text { V42, Organ or tissue replaced by transplant: } \\
\text { V42.0, Kidney }\end{array}$ \\
\hline & & V45, Other postprocedural states \\
\hline & & V45.1x, Renal dialysis status \\
\hline & & V56.xx, Encounter for dialysis and dialysis catheter care \\
\hline \multirow[t]{2}{*}{$\begin{array}{l}\text { II. Lower risk (BP goal }<140 / 90 \\
\text { mmHg) }\end{array}$} & $\begin{array}{l}\text { No diabetes diagnoses } \\
\quad \text { (see above) }\end{array}$ & \\
\hline & $\begin{array}{l}\text { No chronic kidney disease } \\
\text { diagnoses (see above) }\end{array}$ & \\
\hline
\end{tabular}

Data from Chobanian AV, Bakris GL, Black HR, et al. Seventh report of the Joint National Committee on Prevention, Detection, Evaluation, and Treatment of High Blood Pressure. Hypertension 2003;42:1205-52 (http://www.nhlbi.nih.gov/guidelines/hypertension/ jnc7full.htm); and the 2009 ICD-9-CM (http://icd9 cm.chrisendres.com/).

*See Figure 1.

Appendix Table 2. International Classification of Diseases, Ninth Revision, Code Criteria for Comorbidity and Coronary Heart Disease (CHD) Risk Factors Used to Construct the National Cholesterol Education Program Guideline Concordance Algorithm*

Coronary heart disease

CHD equivalent

Diabetes

Peripheral arterial disease 410.xx, Acute myocardial infarction

411.xx, Other acute and subacute forms of ischemic heart disease

412, Old myocardial infarction

413.x, Angina pectoris

414.xx, Other forms of chronic ischemic heart disease

429 , Ill-defined descriptions and complications of heart disease

429.7 Certain sequelae of myocardial infarction, not elsewhere classified

429.71 Acquired cardiac septal defect

429.79 Other

V45, Other postprocedural states

V45.8, Other postprocedural status

V45.81, Aortocoronary bypass status

V45.82 Percutaneous transluminal coronary angioplasty status

249.xx, Secondary diabetes mellitus

250.xx, Diabetes mellitus

648 , Other current conditions in the mother classifiable elsewhere, but complicating pregnancy, childbirth, or the puerperium

648.0 Diabetes mellitus

440.xx, Atherosclerosis

443 , Other peripheral vascular disease

443.8, Other specified peripheral vascular diseases

443.81, Peripheral angiopathy in diseases classified elsewhere

443.9, Peripheral vascular disease, unspecified 
Cerebral vascular disease

Abdominal aortic aneurysm

Risk factors used in assessing risk category for primary prevention ${ }^{\dagger}$

HDL cholesterol

Age

Cigarette smoking

Hypertension

Low HDL cholesterol

High HDL cholesterol

Family history of premature CHD

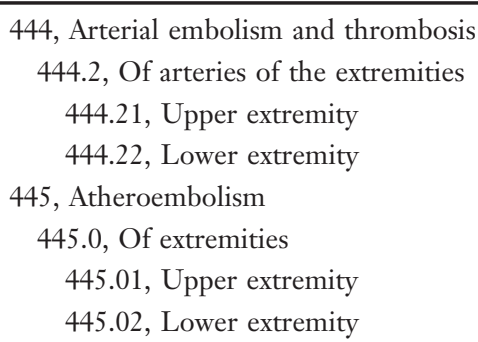

V12.54, Transient ischemic attack and cerebral infarction without residual deficits

441, Aortic aneurysm and dissection

$$
\begin{aligned}
& \text { 441.0, Dissection of aorta } \\
& \text { 441.02, Abdominal } \\
& \text { 441.03, Thoracoabdominal }
\end{aligned}
$$

441.3, Abdominal aneurysm, ruptured

441.4, Abdominal aneurysm without mention of rupture

441.5, Aortic aneurysm of unspecified site, ruptured

441.6, Thoracoabdominal aneurysm, ruptured

441.7, Thoracoabdominal aneurysm, without mention of rupture

441.9, Aortic aneurysm of unspecified site without mention of rupture

$$
\geq 60 \mathrm{mg} / \mathrm{dL}(-1)
$$

Men, $\geq 45$ years; women $\geq 55$ years (1)

Yes (1)

$\mathrm{BP} \geq 140 / 90 \mathrm{mmHg}$ (average of 2 most recent measurements) or taking antihypertensive medication (1)

$<40 \mathrm{mg} / \mathrm{dL}(1)$

$\geq 60 \mathrm{mg} / \mathrm{dL}(-1)$

CHD in male first-degree relative $<55$ years old; CHD in female first-degree relative $<65$ years old (not consistently available in DARTNet) (1)

Data from Ref. 14 or http://www.nhlbi.nih.gov/guidelines/cholesterol/atp3_rpt.htm and the 2009 ICD-9-CM (http://icd9 cm.chrisendres.com/).

*See Figure 3.

${ }^{\dagger}$ In patients without CHD or CHD equivalent. Risk factor score is the sum of bolded numbers in parentheses at end of statements $1-6$.

BP, blood pressure; HDL, high-density lipoprotein. 
Appendix Table 3. International Classification of

Diseases, Ninth Revision (ICD-9), Diagnostic Code

Clusters for Morbidity Assessment in Ambulatory Care

ICD-9 Codes to Include

\begin{tabular}{|c|c|c|c|}
\hline \multirow[b]{2}{*}{ No. } & \multirow[b]{2}{*}{ Diagnostic/Process Cluster } & \\
\hline & & From & To \\
\hline \multirow[t]{4}{*}{1} & \multirow[t]{4}{*}{ Hernia (external abdominal) } & 550 & \\
\hline & & 551.0 & 551.2 \\
\hline & & 552.0 & 552.2 \\
\hline & & 553.0 & 553.2 \\
\hline 2 & Abdominal pain & 789 & \\
\hline \multirow[t]{3}{*}{3} & \multirow{3}{*}{$\begin{array}{l}\text { Acne, diseases of sweat and } \\
\text { sebaceous glands }\end{array}$} & 695.3 & \\
\hline & & 705 & 705.9 \\
\hline & & 706.0 & 706.9 \\
\hline \multirow[t]{4}{*}{4} & \multirow{4}{*}{$\begin{array}{l}\text { Intestinal infectious diseases/ } \\
\text { scute gastroenteritis }\end{array}$} & 001 & 005.9 \\
\hline & & 006.0 & 006.2 \\
\hline & & 007 & 009 \\
\hline & & 558.9 & \\
\hline 5 & Acute sprains, strains & 840 & 848.9 \\
\hline \multirow[t]{3}{*}{6} & \multirow{3}{*}{$\begin{array}{l}\text { Adverse effects of medicinal } \\
\text { agents }\end{array}$} & 960 & 979.9 \\
\hline & & 995 & 995.2 \\
\hline & & 995.4 & \\
\hline \multirow[t]{4}{*}{7} & \multirow[t]{4}{*}{ Alcohol and drug abuse } & 291 & 292.9 \\
\hline & & 303 & 305.8 \\
\hline & & 571.0 & 571.3 \\
\hline & & 648.3 & \\
\hline 8 & Allergic reaction & 995.3 & \\
\hline \multirow[t]{2}{*}{9} & Allergy treatment/desensitization & V07.1 & \\
\hline & & V72.7 & \\
\hline 10 & $\begin{array}{l}\text { Iron deficiency and other } \\
\text { deficiency anemias }\end{array}$ & 280 & 281.9 \\
\hline \multirow[t]{2}{*}{11} & Arrhythmia & 427 & 427.9 \\
\hline & & 785.0 & \\
\hline 12 & Asthma & 493 & 493.9 \\
\hline 13 & Breast lump & 611.72 & \\
\hline 14 & Burns & 940 & 949.9 \\
\hline \multirow[t]{4}{*}{15} & Bursitis, dynovitis, tenosynovitis & 726 & \\
\hline & & 727.00 & 727.01 \\
\hline & & 727.04 & 727.9 \\
\hline & & 727.2 & 727.3 \\
\hline \multirow[t]{5}{*}{16} & Cataract, aphakia & 366 & 366.9 \\
\hline & & $379.3 x$ & \\
\hline & & $743.3 x$ & \\
\hline & & 998.82 & \\
\hline & & V45.61 & \\
\hline 17 & Cerebral vascular disease/CVA & 430 & 438.9 \\
\hline 18 & Chest pain & $786.5 x$ & \\
\hline 19 & Heart failure & 428 & $428.9 \mathrm{x}$ \\
\hline
\end{tabular}

Continued
Appendix Table 3. Continued

\begin{tabular}{|c|c|c|c|}
\hline \multirow[b]{2}{*}{ No. } & \multirow[b]{2}{*}{ Diagnostic/Process Cluster } & \multicolumn{2}{|c|}{$\begin{array}{l}\text { ICD-9 Codes to } \\
\text { Include }\end{array}$} \\
\hline & & From & To \\
\hline \multirow[t]{6}{*}{20} & \multirow[t]{6}{*}{ Conjunctivitis, keratitis } & 053.21 & \\
\hline & & 054.42 & 054.43 \\
\hline & & 077 & $077.9 x$ \\
\hline & & 130.1 & \\
\hline & & 370 & 370.9 \\
\hline & & 372 & $372.3 x$ \\
\hline 21 & Contraception & $\mathrm{v} 25.0$ & v25.9 \\
\hline \multirow[t]{3}{*}{22} & \multirow[t]{3}{*}{$\mathrm{COPD} /$ chronic bronchitis } & 491 & 492.9 \\
\hline & & 494 & 494.9 \\
\hline & & 496 & 496.9 \\
\hline \multirow[t]{3}{*}{23} & \multirow[t]{3}{*}{ Deafness } & 387 & 387.9 \\
\hline & & 388.2 & \\
\hline & & 389 & 389.9 \\
\hline 24 & Degenerative joint disease & 715 & $717 . x$ \\
\hline \multirow[t]{8}{*}{25} & \multirow{8}{*}{$\begin{array}{l}\text { Depression, anxiety, neuroses } \\
\text { (nonpsychotic) }\end{array}$} & 300.0 & \\
\hline & & 300.4 & \\
\hline & & 300.5 & \\
\hline & & 306 & \\
\hline & & 308 & 309 \\
\hline & & 311 & \\
\hline & & 313 & \\
\hline & & 799.2 & \\
\hline \multirow[t]{3}{*}{26} & \multirow[t]{3}{*}{ Dermatitis and eczema } & 690 & 693.9 \\
\hline & & 698.2 & 698.4 \\
\hline & & 706.3 & \\
\hline 27 & Dermatophytosis & 110 & 111.9 \\
\hline \multirow[t]{2}{*}{28} & Diabetes mellitus & 250 & \\
\hline & & 648.0 & \\
\hline \multirow[t]{3}{*}{29} & Diaphragmatic hernia & 551.3 & \\
\hline & & 552.3 & \\
\hline & & 553.3 & \\
\hline 30 & Disease of hair and hair follicles & 704 & 704.9 \\
\hline 31 & Diverticular disease & 562 & \\
\hline \multirow[t]{5}{*}{32} & \multirow{5}{*}{$\begin{array}{l}\text { Thrombophlebitis, pulmonary } \\
\text { embolism }\end{array}$} & 415.1 & \\
\hline & & 451 & \\
\hline & & 453 & \\
\hline & & 673 & \\
\hline & & V12.51 & V12.52 \\
\hline 33 & Impacted cerumen (wax in ear) & 380.4 & \\
\hline 34 & Enlarged tonsils & 474 & \\
\hline 35 & Fibrocystic breast disease & 610 & \\
\hline \multirow[t]{3}{*}{36} & Fibrositis and myalgia & 719.4 & 719.5 \\
\hline & & 729.0 & 729.1 \\
\hline & & 729.4 & 729.5 \\
\hline \multirow[t]{2}{*}{37} & Foreign body in eye & 930 & 930.9 \\
\hline & & $360.5 x$ & 360.6 \\
\hline 38 & Fractures and dislocations & 800 & 839.9 \\
\hline 39 & Ganglion & $727.4 \mathrm{x}$ & \\
\hline 40 & $\begin{array}{l}\text { Gall bladder and biliary tract } \\
\text { diseases }\end{array}$ & 574 & 576.9 \\
\hline
\end{tabular}

Continued 
Appendix Table 3. Continued

\begin{tabular}{|c|c|c|c|}
\hline \multirow[b]{2}{*}{ No. } & \multirow[b]{2}{*}{ Diagnostic/Process Cluster } & \multicolumn{2}{|c|}{$\begin{array}{l}\text { ICD-9 Codes to } \\
\text { Include }\end{array}$} \\
\hline & & From & To \\
\hline 41 & Glaucoma & 365 & \\
\hline 42 & Gout & 274 & \\
\hline \multirow[t]{4}{*}{43} & Headache & 339 & \\
\hline & & 346 & \\
\hline & & 784 & \\
\hline & & 307.81 & \\
\hline 44 & Hematuria & $599.7 x$ & \\
\hline \multirow[t]{2}{*}{45} & Helminthiasis, scabies, lice & 120 & 129.9 \\
\hline & & 132 & 133.9 \\
\hline \multirow[t]{3}{*}{46} & Hemorrhoids/perirectal disease & 455 & 455.9 \\
\hline & & 565 & 566.9 \\
\hline & & 569 & 569.4 \\
\hline \multirow[t]{3}{*}{47} & Hepatitis/mononucleosis & 070 & \\
\hline & & 075 & \\
\hline & & 573.3 & \\
\hline 48 & Hyperlipidemia & 272 & 272.4 \\
\hline \multirow[t]{3}{*}{49} & Hypertension & 401 & 405.9 \\
\hline & & 437.2 & \\
\hline & & 796.2 & \\
\hline \multirow[t]{2}{*}{50} & Infections of eyelid & 373 & 373.2 \\
\hline & & 373.4 & 373.6 \\
\hline \multirow[t]{4}{*}{51} & Infertility & 606 & \\
\hline & & 628 & \\
\hline & & v26.0 & v26.2 \\
\hline & & v26.8 & v26.9 \\
\hline \multirow[t]{2}{*}{52} & Irritable bowel syndrome & 564.1 & \\
\hline & & 564.5 & \\
\hline \multirow[t]{4}{*}{53} & Ischemic heart disease & 410 & 414.9 \\
\hline & & 429.7 & \\
\hline & & V45.81 & \\
\hline & & V45.82 & \\
\hline 54 & Keratoses & 702.0 & 702.1 \\
\hline \multirow[t]{16}{*}{55} & Lacerations/contusions & 530.7 & \\
\hline & & 618.7 & \\
\hline & & 620.6 & \\
\hline & & 622.3 & \\
\hline & & 623.4 & \\
\hline & & 624.4 & \\
\hline & & 664 & \\
\hline & & $665.3 x$ & 665.4 \\
\hline & & $800.1 x$ & \\
\hline & & $800.6 x$ & \\
\hline & & $801.1 x$ & \\
\hline & & $801.6 x$ & \\
\hline & & $803.1 \mathrm{x}$ & \\
\hline & & $803.6 x$ & \\
\hline & & $804.1 x$ & \\
\hline & & $804.6 x$ & \\
\hline
\end{tabular}

Appendix Table 3. Continued

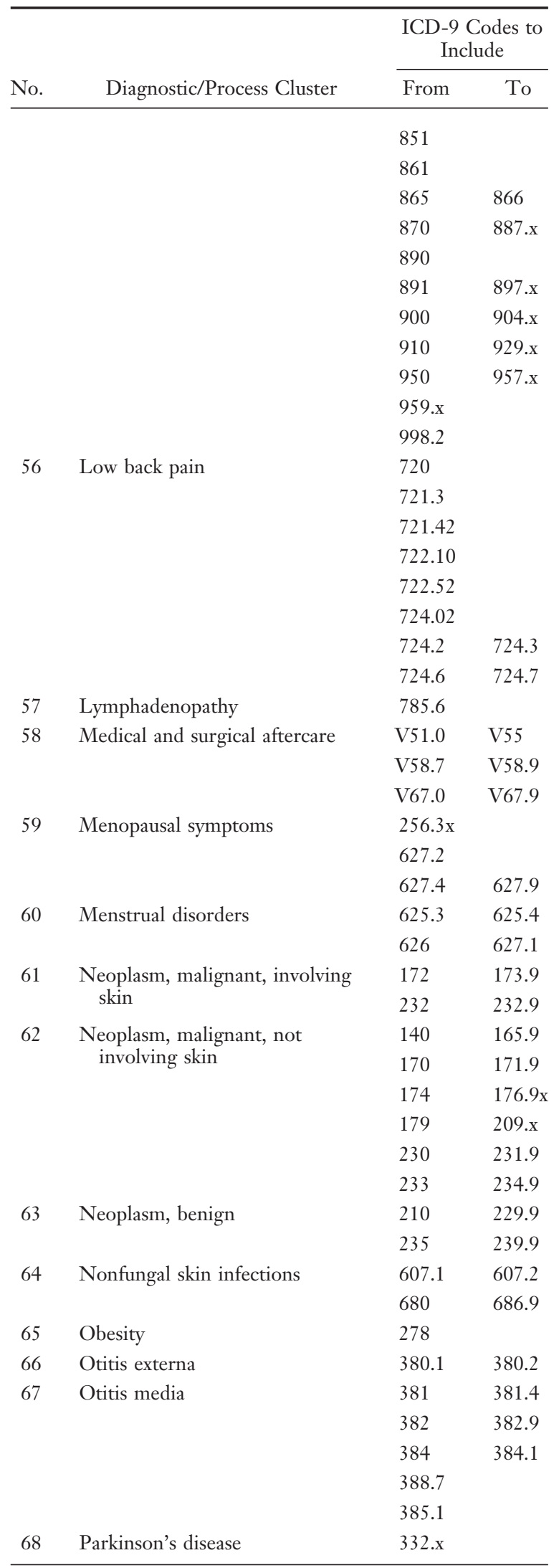

Continued 
Appendix Table 3. Continued

\begin{tabular}{|c|c|c|c|}
\hline \multirow[b]{2}{*}{ No. } & \multirow[b]{2}{*}{ Diagnostic/Process Cluster } & \multicolumn{2}{|c|}{$\begin{array}{l}\text { ICD-9 Codes to } \\
\text { Include }\end{array}$} \\
\hline & & From & To \\
\hline \multirow[t]{3}{*}{69} & Peptic diseases & 530.1 & 530.2 \\
\hline & & 531 & 535.9 \\
\hline & & 530.81 & \\
\hline \multirow[t]{3}{*}{70} & Peripheral neuropathy & 354 & 355.9 \\
\hline & & 356.1 & 356.4 \\
\hline & & 357 & 357.9 \\
\hline \multirow[t]{2}{*}{71} & Peripheral vascular disease & 440.2 & 440.4 \\
\hline & & 443.x & \\
\hline 72 & Personality disorders & 301 & 301.9 \\
\hline \multirow[t]{7}{*}{73} & Pregnancy and abortion & $630 . x$ & $633 x$ \\
\hline & & $634 . x$ & 639.9 \\
\hline & & 640 & 646.4 \\
\hline & & 646.7 & 646.9 \\
\hline & & 650 & 666.x \\
\hline & & 670 & 677.x \\
\hline & & $\mathrm{v} 22.0$ & v24.9 \\
\hline 74 & $\begin{array}{l}\text { Prostatitis and benign prostatic } \\
\text { hypertrophy }\end{array}$ & 600.0 & 601.9 \\
\hline 75 & Psoriasis/pityriasis & 696 & 696.9 \\
\hline 76 & Psychosocial problem & v60.0 & v62.9 \\
\hline 77 & Refractive errors & 367.0 & 367.9 \\
\hline 78 & Renal calculi & 592.0 & 592.9 \\
\hline \multirow[t]{6}{*}{79} & Respiratory tract infection, acute & 032.0 & 034.9 \\
\hline & upper & 460 & 460.9 \\
\hline & & 462 & 465.9 \\
\hline & & 475 & 475.9 \\
\hline & & 487.1 & 487.9 \\
\hline & & 519.8 & \\
\hline \multirow[t]{3}{*}{80} & Respiratory tract infection, acute & 466 & 466.9 \\
\hline & lower & 480 & 488 \\
\hline & & 490 & 490.9 \\
\hline 81 & Rheumatoid diseases & 714 & 714.9 \\
\hline \multirow[t]{3}{*}{82} & Rhinitis, chronic & 472.0 & \\
\hline & & 472.2 & \\
\hline & & 477 & 477.9 \\
\hline \multirow[t]{9}{*}{83} & Routine health maintenance & V01.0 & V07.0 \\
\hline & & V07.2 & V07.9 \\
\hline & & V20.0 & V21.9 \\
\hline & & V28.0 & V28.9 \\
\hline & & V30.0 & V37.9 \\
\hline & & V39.0 & V39.9 \\
\hline & & V65.5 & \\
\hline & & V70.0 & V72.6 \\
\hline & & V72.8 & V82.9 \\
\hline 84 & $\begin{array}{l}\text { Schizophrenia and affective } \\
\text { psychosis }\end{array}$ & 295 & 298.9 \\
\hline 85 & Scoliosis/kyphosis & 737 & 737.9 \\
\hline
\end{tabular}

Continued
Appendix Table 3. Continued

\begin{tabular}{|c|c|c|c|}
\hline \multirow[b]{2}{*}{ No. } & \multirow[b]{2}{*}{ Diagnostic/Process Cluster } & \multicolumn{2}{|c|}{$\begin{array}{l}\text { ICD-9 Codes to } \\
\text { Include }\end{array}$} \\
\hline & & From & To \\
\hline \multirow[t]{3}{*}{86} & Seizure disorder & 345 & 345.9 \\
\hline & & 780.3 & \\
\hline & & 779.0 & \\
\hline \multirow[t]{6}{*}{87} & Sexually transmitted diseases & 054.1 & \\
\hline & & 090 & 99.9 \\
\hline & & 112.1 & 112.2 \\
\hline & & 608 & \\
\hline & & 614 & 614.99 \\
\hline & & $616 . x$ & \\
\hline \multirow[t]{2}{*}{88} & Sinusitis & 461 & 461.9 \\
\hline & & 473 & 473.9 \\
\hline 89 & Skin ulcer & 707 & 707.9 \\
\hline 90 & Strabismus & 378 & 378.9 \\
\hline \multirow[t]{2}{*}{91} & Thyroid disease & 240 & 246.9 \\
\hline & & 648.1 & \\
\hline \multirow[t]{2}{*}{92} & Urethral stricture & 598 & 598.9 \\
\hline & & 753.6 & \\
\hline \multirow[t]{6}{*}{93} & Urinary tract infection & 590 & 590.9 \\
\hline & & 595 & 595.9 \\
\hline & & 599.0 & \\
\hline & & 646.5 & 646.6 \\
\hline & & 771.82 & \\
\hline & & V13.02 & \\
\hline \multirow[t]{2}{*}{94} & Urticaria & 708 & 708.9 \\
\hline & & 995.1 & \\
\hline 95 & Uterine prolapse & 618.1 & 618.4 \\
\hline \multirow[t]{5}{*}{96} & Vaginitis & 112.1 & \\
\hline & & 131.00 & 131.01 \\
\hline & & 616.1 & \\
\hline & & 623.5 & \\
\hline & & 627.3 & \\
\hline \multirow[t]{4}{*}{97} & Valvular heart disease & 391.1 & \\
\hline & & 391.9 & \\
\hline & & 394 & 397.9 \\
\hline & & 424 & 424.9 \\
\hline 98 & Varicose veins & 454 & 454.9 \\
\hline \multirow[t]{2}{*}{99} & Vertiginous syndromes & 386 & 386.9 \\
\hline & & 780.4 & \\
\hline \multirow[t]{2}{*}{100} & Viral exanthem & 051 & 059.x \\
\hline & & 74.3 & \\
\hline 101 & Warts & 78.1 & \\
\hline \multirow[t]{6}{*}{102} & Chronic kidney disease & 403 & 404.x \\
\hline & & 581 & $582 . \mathrm{x}$ \\
\hline & & 585 & 586 \\
\hline & & V42.0 & \\
\hline & & V45.11 & V45.12 \\
\hline & & V56.xx & \\
\hline 103 & Abdominal aortic aneurysm & 441.xx & \\
\hline
\end{tabular}

COPD, chronic obstructive pulmonary disorder; CVA, cerebrovascular accident. 
Appendix Table 4. Forward Logistic Regression Model of Patient-Level Factors with Blood Pressure Noncontrol per Seventh Report of the Joint National Committee on Prevention, Detection, Evaluation, and Treatment of High Blood Pressure Guideline*

\begin{tabular}{|c|c|c|c|c|}
\hline Covariate & Parameter Estimate & $P$ Value & Odds Ratio (95\% CI) & Cumulative C-Index \\
\hline Intercept & -3.1521 & $<.0001$ & & \\
\hline Hypertension & 1.7286 & $<.0001$ & $5.63(5.46-5.81)$ & 0.735 \\
\hline Diabetes mellitus & 1.5772 & $<.0001$ & $4.84(4.64-5.06)$ & 0.764 \\
\hline \multicolumn{5}{|l|}{ Body mass index $\left(\mathrm{kg} / \mathrm{m}^{2}\right)$} \\
\hline$<18.5$ (underweight) & -0.0544 & .45 & $0.95(0.82-1.09)$ & 0.802 \\
\hline $18.5-24.9$ (normal) & Reference & & & \\
\hline 25.0-29.9 (overweight) & 0.4171 & $<.0001$ & $1.52(1.46-1.58)$ & 0.802 \\
\hline $30.0-34.9$ (obesity, class I) & 0.7208 & $<.0001$ & $2.06(1.97-2.14)$ & 0.802 \\
\hline 35.0-39.9 (obesity, class II) & 0.9440 & $<.0001$ & $2.57(2.44-2.71)$ & 0.802 \\
\hline$>40.0$ (obesity, class III) & 1.1896 & $<.0001$ & $3.29(3.09-3.50)$ & 0.802 \\
\hline \multicolumn{5}{|l|}{ Visits (n) } \\
\hline $1-2$ & Reference & & & \\
\hline $3-4$ & -0.2921 & $<.0001$ & $0.75(0.72-0.77)$ & 0.806 \\
\hline $5-6$ & -0.3149 & $<.0001$ & $0.73(0.69-0.77)$ & 0.806 \\
\hline$>6$ & -0.3348 & $<.0001$ & $0.72(0.68-0.75)$ & 0.806 \\
\hline \multicolumn{5}{|l|}{ Age (years) } \\
\hline $18-40$ & Reference & & & \\
\hline $41-60$ & -0.3831 & $<.0001$ & $1.47(1.42-1.52)$ & 0.812 \\
\hline $61-80$ & 0.6374 & $<.0001$ & $1.89(1.81-1.98)$ & 0.812 \\
\hline$>80$ & 0.9475 & $<.0001$ & $2.58(2.38-2.79)$ & 0.812 \\
\hline Male sex & 0.3835 & $<.0001$ & $1.47(1.43-1.51)$ & 0.817 \\
\hline Hyperlipidemia & -0.2812 & $<.0001$ & $0.75(0.73-0.78)$ & 0.818 \\
\hline Kidney disease, chronic & 0.8324 & $<.0001$ & $2.30(2.09-2.53)$ & 0.819 \\
\hline Ischemic heart disease & -0.4755 & $<.0001$ & $0.62(0.58-0.67)$ & 0.820 \\
\hline Prostatitis and benign prostatic hyperplasia & -0.3367 & $<.0001$ & $0.71(0.67-0.76)$ & 0.821 \\
\hline
\end{tabular}

*Number of observations read: 227,123; number of observations used: 209,582.

$\mathrm{CI}$, confidence interval. 
Appendix Table 5. Forward Logistic Regression Model of Patient-Level Factors Associated with Low-Density Lipoprotein Cholesterol Noncontrol per the National Cholesterol Education Program Guideline*

\begin{tabular}{|c|c|c|c|c|}
\hline Covariate & Parameter Estimate & $P$ Value & Odds Ratio (95\% CI) & Cumulative C-Index \\
\hline Intercept & -3.3493 & $<.0001$ & & \\
\hline Hyperlipidemia & 0.9236 & $<.0001$ & $2.52(2.43-2.61)$ & 0.654 \\
\hline Diabetes mellitus & 0.8920 & $<.0001$ & $2.44(2.33-2.56)$ & 0.682 \\
\hline \multicolumn{5}{|l|}{ Body mass index $\left(\mathrm{kg} / \mathrm{m}^{2}\right)$} \\
\hline$<18.5$ (underweight) & 0.0269 & .78 & $1.03(0.85-1.25)$ & 0.710 \\
\hline $18.5-24.9$ (normal) & Reference & & & \\
\hline 25.0-29.9 (overweight) & 0.4519 & $<.0001$ & $1.57(1.50-1.65)$ & 0.710 \\
\hline 30.0-34.9 (obesity, class I) & 0.6028 & $<.0001$ & $1.83(1.73-1.92)$ & 0.710 \\
\hline 35.0-39.9 (obesity, class II) & 0.6231 & $<.0001$ & $1.86(1.75-1.99)$ & 0.710 \\
\hline$\geq 40.0$ (obesity, class III) & 0.6632 & $<.0001$ & $1.94(1.79-2.10)$ & 0.710 \\
\hline \multicolumn{5}{|l|}{ Age (years) } \\
\hline $18-40$ & Reference & & & \\
\hline $41-60$ & 0.5888 & $<.0001$ & $1.80(1.72-1.89)$ & 0.719 \\
\hline $61-80$ & 0.4737 & $<.0001$ & $1.61(1.52-1.70)$ & 0.719 \\
\hline$>80$ & 0.5006 & $<.0001$ & $1.65(1.48-1.83)$ & 0.719 \\
\hline Cerebral vascular disease/CVA & 0.9993 & $<.0001$ & $2.72(2.49-2.96)$ & 0.726 \\
\hline Male sex & 0.2206 & $<.0001$ & $1.25(1.20-1.29)$ & 0.731 \\
\hline \multicolumn{5}{|l|}{ Visits/year (n) } \\
\hline $1-2$ & Reference & & & \\
\hline $3-4$ & -0.1678 & $<.0001$ & $0.85(0.81-0.88)$ & 0.731 \\
\hline $5-6$ & -0.1625 & $<.0001$ & $0.85(0.80-0.90)$ & 0.731 \\
\hline$>6$ & -0.2212 & $<.0001$ & $0.80(0.76-0.84)$ & 0.731 \\
\hline Alcohol and drug abuse & 0.3537 & $<.0001$ & $1.42(1.34-1.52)$ & 0.733 \\
\hline Anemia & -0.3073 & $<.0001$ & $0.74(0.68-0.79)$ & 0.733 \\
\hline Hypertension & 0.1848 & $<.0001$ & $1.20(1.16-1.25)$ & 0.734 \\
\hline
\end{tabular}

*Number of observations read: 136,771; number of observations used: 131,589.

CI, confidence interval; CVA, cerebrovascular accident. 
Figure A1. Risk-adjusted percentage of patients with uncontrolled blood pressure (BP), by clinic.

RISK-ADJUSTED PERCENT NOT AT BP GOAL

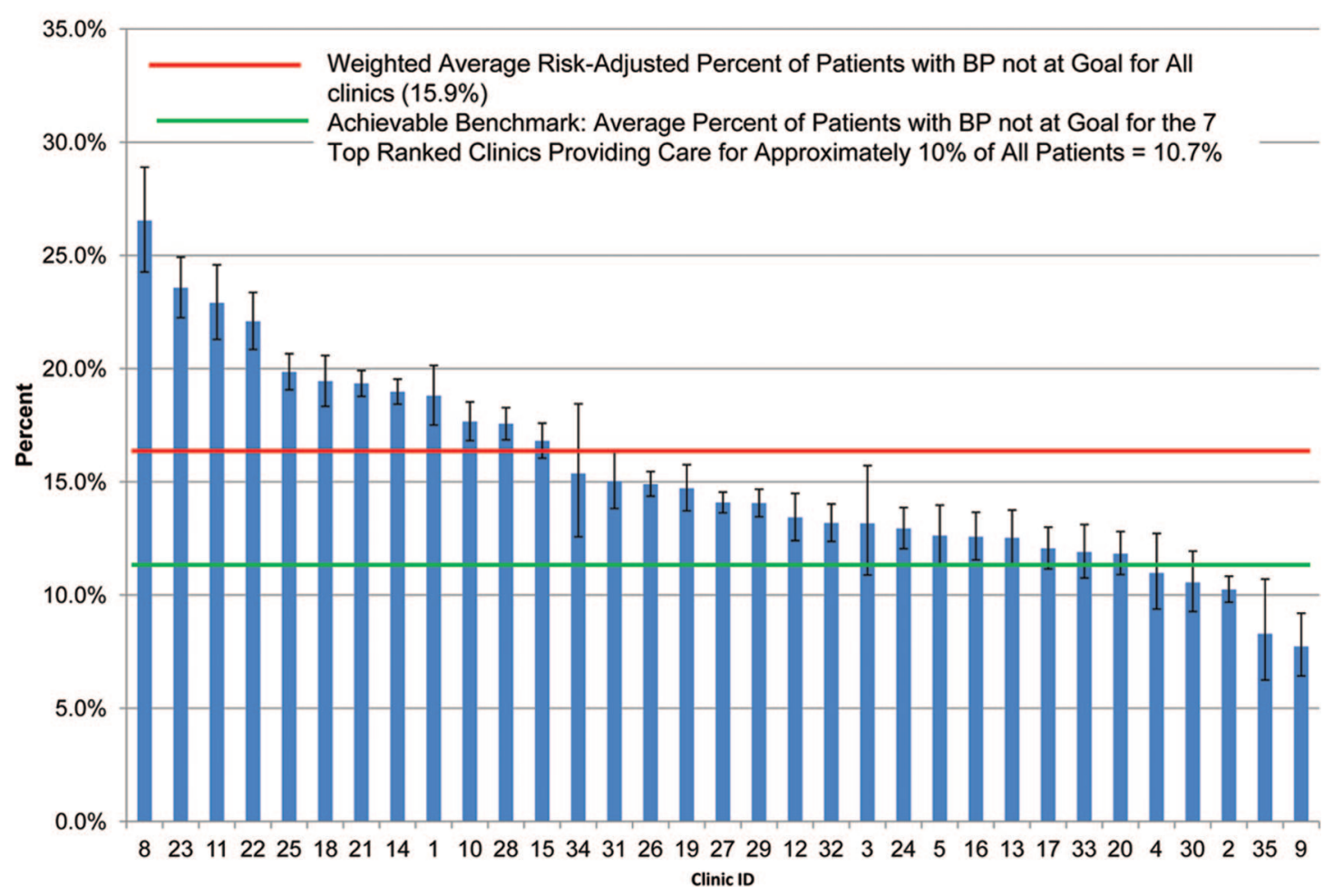

Figure A2. Risk-adjusted percentage of patients with uncontrolled low-density lipoprotein (LDL)-cholesterol, by clinic.

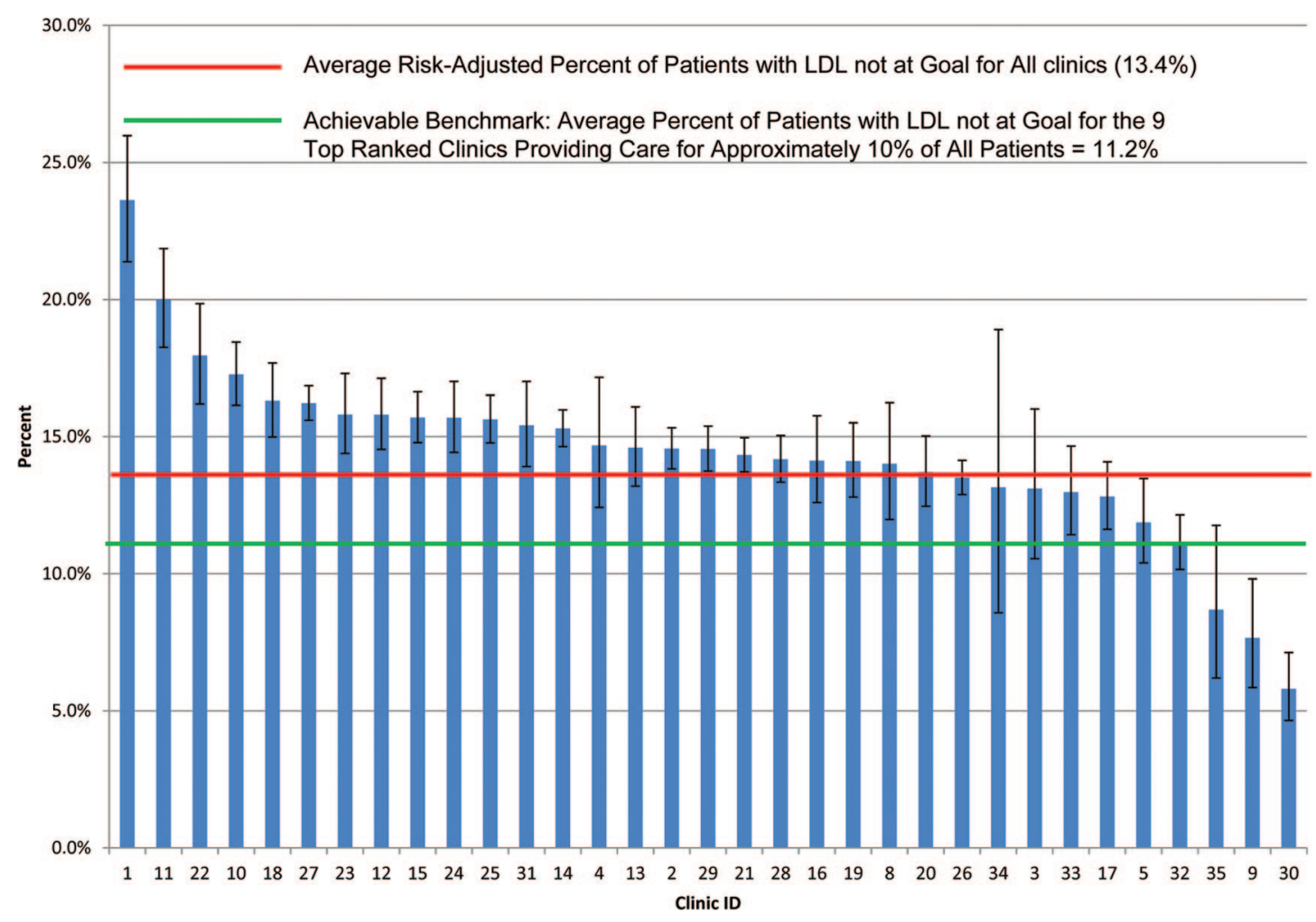

